\title{
How Parents and Their Children View Media? Comparing Attitudes of Parents and Children towards Media
}

\author{
Prerna Varma ${ }^{1}$
}

\section{ABSTRACT}

Newspaper to Blog, Broadcast television to Internet television, $35 \mathrm{~mm}$ film to digital image, telephone to instant message and tape player to iPod. Our world and our communications technologies continue to change as the traditional mass media of print, radio; television and films have morphed into Web-enabled cell phones, iPods, satellite radios and online news. A number of researches have been done to study the effect of media and its influences. But they fail to acknowledge what particular attitudes people from different age group have towards media. This project attempts to examine and compare the attitudes of parents and children towards mass media and general and traditional and digital media in particular. The findings presented in this report have been concluded from Questionnaire surveys and interviews of 120 subjects in the age group of 9-45 year old. It explores media consumption, knowledge and exposure towards various types of mass media, attitudes towards television and advertising, knowledge and attitude towards government's intervention in mass media, attitudes towards the changing trends in media and advent of internet, newspaper readership and opinions towards various sources of information particularly newspapers and news channels.

Keywords: Attitude Towards Internet, Attitudes Towards Media, Children And Media, Digital Media, Media Influences

In the late 1940's, to listen to the radio, a house needed electricity. One needed to put the radio near an electrical outlet, with the furniture positioned so the family could listen to programs. In 1980's television was a rage and people would put antenna on the roof so that they could watch their new television set. If one had no television, they were supposed to run to their neighbours and watch shows like 'Buniyaad' and 'Humlog'. In the late 1990's and early 2000's, India saw the advent of computer and people were attracted to this bliss. For more than half a century, people arranged their room furniture to accommodate the cable or satellite or telephone lines so that they can experience the miracle of media that connected people from world-over and quenched human curiosity along with the need for entertainment.

\footnotetext{
${ }^{1}$ Bachelors of Arts (Hons). (Applied Psychology

(C) 2015 I P Varma; licensee IJIP. This is an Open Access Research distributed under the terms of the Creative Commons Attribution License (http://creativecommons.org/licenses/by/2.0), which permits unrestricted use, distribution, and reproduction in any Medium, provided the original work is properly cited.
} 


\section{How Parents and Their Children View Media? Comparing Attitudes of Parents and Children towards Media}

Media has grown since then, the technology now transformed into mass media wireless, also called Wi-Fi, an abbreviation for Wireless Fidelity. New technologies have changed the way people, think and act. What was once an experience of a lifetime is now experienced every day. Thanks to media, people can watch movies on their laptops topping on their laps, listen to music from radio, download games and applications on their latest iPad, read newspapers online and contact to their friends instantly through Blackberry messenger.

The mass media which about two decades ago was a source of pleasure and entertainment now encapsulates a major part of our life. It has grown from being a part of our drawing room and reached our bedroom, changing the way we think, act, feel and opine. Mass media and its transformation has led to an incredible change in our lives and our attitude towards the world and media itself through instant broadcasting and connecting.

\section{Mass Media: From Newspaper to Internet}

Derived from the word 'medium', media in general refers to various means of communication. For example, television, radio, and the newspaper are different types of media. The term can also be used as a collective noun for the press or news reporting agencies. In the computer world, "media" is also used as a collective noun, but refers to different types of data storage options.

As defined by techterms.com, "Mass media refers collectively to all media technologies, including the Internet, television, newspapers, and radio, which are used for mass communications, and to the organizations which control these technologies.”

According to the business dictionary, mass media includes following aspects:

1. Communication channels through which news, entertainment, education, data, or promotional messages are disseminated. Media includes every broadcasting and narrowcasting medium such as newspapers, magazines, TV, radio, billboards, direct mail, telephone, fax, and internet.

2. Data storage material divided into three broad categories according to the recording method: (1) Magnetic, such as diskettes, disks, tapes, (2) Optical, such as microfiche, and (3) MagnetoOptical, such as CDs, and DVDs.

By definition, mass communication is a message created by a person or a group of people sent through a transmitting device (a medium) to a large audience or market.

Therefore, Mass media are media, which can be used to communicate and interact with a large number of audiences. Be it the pictorial messages of the early ages, or the high-technology media that are available today, one thing that we all agree upon, is that mass media are an inseparable part of our lives. Entertainment and media always go hand in hand, but in addition to the 


\section{How Parents and Their Children View Media? Comparing Attitudes of Parents and Children towards Media}

entertainment, mass media also remain to be an effective medium for communication, dissemination of information, advertising, marketing and in general, for expressing and sharing views, opinions and ideas.

\section{TYPES OF MEDIA}

Print Media: The print media includes newspapers, magazines, brochures, newsletters, books and even leaflets and pamphlets. Visual media like photography can also be mentioned under this sub-head, since photography is an important mass media, which communicates via visual representations. Although, it is said that the electronic or new media have replaced the print media, there exists a majority of audiences who prefer the print media for various communication purposes. Public speaking and event organizing can also be considered as a form of mass media. Electronic Media: For many people, it is impossible to imagine a life without their television sets, be it the daily news dose or even the soap operas. This mass media includes television and radio. This category also includes electronic media like movies, CDs and DVDs as well as the new hottest electronic gadgets. New-age Media: With the advent of new technologies like Internet, we are now enjoying the benefits of high technology mass media, which is not only faster than the old-school mass media, but also has a widespread range. Mobile phones, computers and Internet are often referred to as the new-age media. Internet has opened up several new opportunities for mass communication which include email, websites, blogging, Internet TV and many other mass media which are booming today. In brief, different Types of Media are Advertising media, various media, content, buying and placement for advertising Electronic media, communications delivered via electronic or electromechanical energy Digital media, electronic media used to store, transmit, and receive digitized information Electronic Business Media, digital media for electronic business Hypermedia, media with hyperlinks Multimedia, communications that incorporate multiple forms of information content and processing Print media, communications delivered via paper or canvas Published media, any media made available to the public Mass media, all means of mass communication Broadcast media, communications delivered over mass electronic communication networks News media, mass media focused on communicating news News media (United States), the news media of the United States of America New media, media that can only be created or used with the aid of modern computer processing power Recording media, devices used to store information

Social media, media disseminated through social interaction.

\section{Attitudes -general or individualistic}

An attitude is a hypothetical construct that represents an individual's degree of like or dislike for something. Attitudes are generally positive or negative views of a person, place, thing, or event - this is often referred to as the attitude object. People can also be conflicted or ambivalent toward an object, meaning that they simultaneously possess both positive and negative attitudes toward the item in question. 


\section{How Parents and Their Children View Media? Comparing Attitudes of Parents and Children towards Media}

As by the psychology dictionary, "An attitude is an opinion that one has about someone or something. It can reflect a favorable, unfavorable, or neutral judgment."

We may have attitudes about many things. For example, we have attitudes about people, political issues, pets, music, art, movies, books, and education.

Attitudes may reflect both beliefs and feelings. For example, a positive attitude concerning a psychology course may include the belief that the course involves learning about something that is important to your life and the feeling that you like the course.

All definitions of attitude agree that attitude is a state of mind, a set of views or thoughts, regarding some topic, generally referred to as the attitude object.

Attitudes may be general such as common men's dislike for terrorists and people propagating terrorism. At the same time they may be individualistic, such as a girl holding a positive view about 'Barbie dolls' while a boy is having a negative attitude towards the same object.

Attitudes generally refer to the way people think about certain objects, places, people and events. They therefore also define the way people act. An attitude towards a particular object can help one pre-determine an individual's behaviour towards it. For example, in the same instance referred above, the girl with positive attitude towards the doll would preferably play with, make her hair or change her dress, whereas the boy might throw the doll or keep it aside and play with something else.

\section{Attitudes and media effects}

Most people accept the idea that the media can influence people. But the degree of that influence, as well as who is most-impacted, when, how and why, have been subjects of great debate about communication scholars for nearly a century now. Media effects refers to the many ways individuals and society may be influenced by both news and entertainment mass media, including films, television, radio, newspapers, books, magazines, websites, video games and music.

But media's influence and effects rely on the attitudes or viewpoints people hold for them. There is a strong likelihood that people who hold a positive view about media and have keenness towards absorbing its tactics are more often influenced by media than those who hold a neutral or a negative view towards media and its tactics.

Hence scholars since decades have opined that children generally have a positive view towards media. That is the probable reason why children are more prone to media violence and why they more often emulate the content presented by media.

These abstractions by scholars have been studied and compared in this project which aims to understand, define and compare the attitudes of children amongst different age groups towards 


\section{How Parents and Their Children View Media? Comparing Attitudes of Parents and Children towards Media}

media along with that of their parents. The project endeavours to answers such questions and form basis for further researches in this field.

\section{REVIEW OF LITERATURE}

Children's attitudes towards media particularly advertising are probably one of the most widely studied phenomenons in researches related to the field of media. To this date however, there has been no attempt to define a standard attitude which guides children behaviour.

The purpose of this study is to understand the attitudes parents and children hold for different types of media. This is done to view how some sets of population are more affected by media and its content than the others. The motive is to understand how these attitudes in defining the way children and parents perceive media and act in relation to it.

A benchmark study was conducted to examine Mainland Chinese parents' attitudes toward advertising and parental mediation of television viewing. A survey of 1,665 parents of elementary school children aged six to fourteen in Beijing, Nanjing and Chengdu was conducted December 2001 to March 2002. Results indicated Chinese parents hold negative attitudes toward television advertising in general and children's advertising specifically. The negative attitudes result mainly from the perception that advertising is deceptive and annoying. Parents feel strongly that advertising should be banned on children's programming. Ninety-eight percent of parents exercise some control over the contents and time of television viewing. Despite a low level of co-viewing and discussion of television commercials with children, Chinese parents perceived that they have great influence on their children's attitudes toward advertising.

While one reviews literature for this project, one can notice various researches aimed at studying the attitudes of students towards internet. Technology is great key that social, cultural, political values have been changed. By the improvements at technology, internet becomes a guide to analyse these changes and inform people about changes. By requiring the changes, adaptation for these are needed factor to survive with the effect of globalization and competition. Reaching resources in a fast way and gathering them under the different points of views with the perspectives of equality and alternatives. Although Internet has advantages, it has shortcoming by creating aleniation, addiction and deviance issues and communities. On the other hand, it effects the education cycle of students by providing alternatives learning styles and learning in a creative way issues as an advantages of internet. Gaining advantage is great options for everyone, internet is an aspect of changing life in order to be further step in life. Technological developments open wide range alternative choices to gain benefit for people's life (Forcier, 1996). The great impact about technology requires individuals to be more creative rather than accepting all conditions without questioning. Because technology contributes individual to search lonely in order to get information in a stable and comfortable way. In addition to this, students get various capacities and properties while they are engaging with learning. In that sense, technology makes people to have self-differentiated properties in order to get wide range 


\section{How Parents and Their Children View Media? Comparing Attitudes of Parents and Children towards Media}

of knowledge and about all issues and everyone has same opportunities for gathering this knowledge. Time is main consideration beyond the technology to create active searching about information at this competitive environment. Because of the effects of competitive environment, stable knowledge is needed to get further step at one's life among people. Therefore, we have to realize the perspectives of students about internet as a first step by relating advantage of technology. Internet comes to the point that reflects discovery of data instantly to adapt the changes (Grabe, et al., 2001). Therefore, Internet is the main item for establishing new cultures among societies because of effecting education.

All reflections about the study that is "attitudes of students towards internet" by A Associate Professor Dr. Aytekin ISMAN and senior Instructor Fahme DAVAJ at the the Eastern Mediterranean University in the year 2004, concluded that because of living technology based and knowledge based century, adaptation to technology is inevitable conditions. As known, internet is great option for us to catch information any time we want. There is a consensus that internet provides huge alternatives with its advantages but also it includes different dimensions as a shortcoming. In addition to this, research results represent that high percentages concentrated on positive and consciousness about internet.

Therefore, the results of the research and the questionnaire, students have positive tendency the useful and easy reflections of internet. This examine that there is a consciousness about effects and importance of internet by having tendency to apply the consciousness or willingness of new technological style, because students education levels are convenient to apply and use internet otherwise they cannot reach the competitive environment.

Because of Internet become a part of every people's life, all of the people should eliminate negative perceptions and attitudes about internet and improve their adaptations in order to catch competitive environment strengths. By relating these information, aim of the this study was defined as to make analyse the attitudes of students towards internet as a being first step to do comments on these issues and to realize

The effects at education as being influencer on student's learning through effecting variables which are the personal information about students. As it is obvious that internet has shortcoming and also advantages. This study also targeted to define the awareness of students about negatives aspects of Internet and how they respond by emerging their backgrounds consideration.

As a result, having consciousness and positive reflections about Internet makes people to be further step at competitive environment. Therefore, at education cycle of students concentrate more to learn internet alternatives and functions for getting great positive benefit their future life by adapting contemporary trends. 


\section{How Parents and Their Children View Media? Comparing Attitudes of Parents and Children towards Media}

Various researchers and even layman claim that Television (TV) viewing is one of the most pervasive sedentary pursuits among children and adolescents. Research studies have shown that higher TV viewing hours are associated with a number of negative effects such as being overweight and obese, attention and behavioural problems, and impaired academic performance. Most interventions to reduce time spent watching TV have been school-based and little is known about the strategies that families use to control TV watching time. Hence a qualitative study of New Zealand parents' perceptions and views was done by Dorey, Roberts, Meagher-Lundberg P from University of Auckland in 2009. Herein Six focus groups with Māori, Pacific and nonMāori non-Pacific parents were conducted to examine New Zealand parents' perceptions of their children's TV watching. Focus groups explored attitudes towards TV viewing, strategies used to reduce viewing, and opinion on two different electronic monitors that can be used to restrict TV viewing. Focus group discussions were transcribed and a content analysis was conducted.

Results indicated that parents described TV as playing a dominant role in their family's lives, and highlighted several barriers to reducing children's TV viewing, such as parents not willing to reduce their own TV watching, a lack of safe alternatives to TV and the need to use TV as a babysitting tool. Limiting access to TV, making TV viewing a reward and finding alternative activities were current strategies parents employed to limit TV viewing; however, the barriers highlighted by parents make implementing such strategies difficult. Attitudes towards electronic monitor use to reduce TV viewing were mixed, but suggest further investigation of these devices is needed.

A new report on children's and their parents' attitude towards media consumption was conducted by the Swedish Media Council in year 2006. 2000 children and young people between 9 and 16 years of age and 2000 parents were asked to comment on how they perceive the media in their everyday life. According to the report, Swedish parents have a good control over their children's media consumption - differently from comparative studies in other countries. However, the opinions on what sort of contents are harmful, differ a lot.

Compared to last year's survey, both children and young people are using internet more actively, and the increase is most conspicuous among children ( $9-12$ years).

In their leisure time, the majority of children and young people most often are seeing their friends, doing homework and cultivating some sport.

Dedicating their time to the media - and especially TV - comes next after the above mentioned activities on the list of leisure time activities indicated by children.

The parents have an adequate idea of what their children are doing in their leisure time. "The parents seem to be quite well informed about how much time their children spend on the media. They also seem to have introduced more rules as for media consumption in comparison with last year. The children, however, think that their parents do not sufficiently discuss media-related 


\section{How Parents and Their Children View Media? Comparing Attitudes of Parents and Children towards Media}

impressions with them, as much as parents themselves indicate”, says Ann KatrinAgebäck, administrative director at the Swedish Media Council.

Children and young people agree that they mostly feel bad when they are watching other children suffer, whereas the parents consider sex and pornography to be most harmful. $67 \%$ of the parents think that violence displayed in e.g. TV series is harmful, whereas only $14 \%$ of the children/young people state that they are affected by such violence. In their opinion, the genuine violence in e.g. news is considerably worse.

Studies released by U.S, bishops in the year 2010 suggest that parents want more control over media content.

The study “Parents' Hopes \& Concerns About the Impact of Media on their Children” suggested more than 80 percent of parents are concerned about depictions of violence, sex, illegal drug use, alcohol abuse and profane language in the media-particularly on television programs and Internet sites. Other platforms raising concern were TV ads, social networking sites, video games, music and cell phones.

In a study Conducted by RAND and published in the September 2004 issue of Paediatrics, on 1792 adolescents ages 12-17 showed that watching sex on TV influences teens to have sex. Youths who watched more sexual content where more likely to initiate intercourse and progress to more advanced noncapital sexual activities in the year following the beginning of the study. Youths in the 90th percentile of TV sex viewing had a predicted probability of intercourse initiation that was approximately double that of youths in the 10th percentile. Basically, kids with higher exposure to sex on TV were almost twice as likely as kids with lower exposure to initiate sexual intercourse.

Surveys commissioned by Vetch Electronics and performed by research firm Compass has gauged parental attitudes to video games, by interviewing Canadian parents with children aged three

to

eight.

The survey, conducted with 500 parents by professional interviewers using computer aided telephone interviewing (CATI) between August 3-8, also found that 60 percent of respondents indicated that their eldest child in the age range currently plays games, and 81 percent of parents felt that children spent too much time playing video games.

Further figures in the study, which was commissioned by a maker of educational game software, show that 76 percent of parents whose children currently do not play video games said they would buy video games that motivate children to get involved in learning, and 86 percent of parents felt that educational video games could be helpful for a child's development.

Finally, the survey found that 76 percent of parents are concerned that the content of many video 


\section{How Parents and Their Children View Media? Comparing Attitudes of Parents and Children towards Media}

games is inappropriate for young children, but does not make it clear whether ESRB age ratings were taken into account when answering this question. The research was conducted and published in the year 2005.

Similarly, a 2009 survey research shows the attitude of parents changing towards video games. According to a new study by Xbox 360 manufacturers Microsoft, 61 per cent of parents consider video games a "great social experience".

The results of the second annual "Play Smart, Play Safe" survey, which monitors parents and children's attitudes towards digital entertainment, revealed that 52 per cent of the parents surveyed feel that games bring families together, and that, controversially, 64 per cent allow their children to play video games which have a higher age rating than they should be allowed.

Equally surprising is children's own desire for greater regulation of the games they play.

69 per cent of children want their parents to be more involved in checking the games they play are appropriate, and almost half state that their parents are not vigilant enough and do so "never" or "not enough".

As such, 73 per cent of young games players would turn to a friend as their first port of call for guidance on suitable gaming, in contrast to 23 per cent who would turn to a parent.

The findings were being lauded by Microsoft as part of sea change in society's attitudes to video gaming, with the study referencing a recent report from the European Parliament's Internal Market Committee which claimed video games have a "broadly beneficial effect on the mental development of children".

Our attitudes not only affect the way we perceive media, but media also affects the way we perceive things and determines our attitudes.

There is a growing body of evidence that parental regulation or mediation of their children's media use has consequences for media effects. Research has examined not only the factors which influence parental mediation of children's television viewing but also the effects of parental mediation on children's media use, consumer socialization and media literacy (see Calvert,1999; Singer and Singer, 2001). Parental mediation is, too, influenced by such factors as family interaction or communication styles; these, in turn, have been shown to influence the ability to understand television among young children. For example, in a field study of 627 children and 486 of their parents, Austin et al (1990) examined the effects of family communication environment and parental mediation of television content on third, sixth and ninth graders' perceptions of the realism of television content, its similarity to real life and their identification with television characters. Findings showed that effective interpersonal 16 family 


\section{How Parents and Their Children View Media? Comparing Attitudes of Parents and Children towards Media}

communication helps children form the real world perceptions which they then compare with their perceptions of the television world so as to better assess realism.

These studies clearly indicate how parents and children have differing views about media and how the mass effects of media are a cause of concern. Hence this project aims to understand the attitudes of children and parents towards media and compare these attitudes to understand the major effects media has on children of this generation.

\section{AIM OF THE STUDY}

Comparison of attitudes of children and parents towards media as a research theme was chosen because of the rising concern about the effects of media over children and how parents are trying to curb the negative after effects of media on kids. Attitudes people hold, greatly define the way in which they behave. Hence a positive attitude towards media would result in grabbing all the information and emulating the tactics that media offer, while a negative or neutral attitude can have calming effects. The attempts have been made to study and compare the attitudes parents and children hold towards media and how that effects their media perception.

The aim of this research is to study the attitudes children of different age groups and parents hold towards media and compare them to understand how these attitudes can affect media perception.

The research involves the objective of 'To study and compare attitudes of children and parents towards media and its effect on media perception.'

\section{METHODOLOGY}

\section{Hypothesis}

1. When compared, children will have a positive attitude towards media while parents will have a neutral or negative attitude towards media.

2. A positive attitude towards media will result in positive apperception towards media contents and increase its influence on the individual.

\section{Sampling}

A sample of 120 individuals was taken. Out of a sample of 60 children, 30 were from the age group 8-12 years and 30 were from the age group 13-17 years. The former group had one extra boy while the latter had one extra girl owing to the fact that boys from ages 8-12 and girls from ages 13-17 are more affected by media. A total of 60 parents agreed to participate in the project and the gender ratio was equally divided.

The sampling technique was non random sampling based on proximity and were undertaken from a popular schools in Punjab. The sample group belonged to upper middle class economic status where individuals have access to all types of print and electronic media. 


\section{How Parents and Their Children View Media? Comparing Attitudes of Parents and Children towards Media}

\section{Tools for data collection}

Since no particular tests measures people's attitude towards media, hence personal interviews and questionnaires were used to ascertain the attitudes of the sample population.

Interview is the method of data collection, where information is obtained through face to face verbal means. Interviews can have structured or unstructured questions. A positive rapport is built before the commencement of interview. In this case a set of semi-structured questions were asked from the sample.

Questionnaires are an economical tool of data collection. Items are listed on paper and the individuals may have to answer them in closed or open ended style. In this project, open and closed ended questionnaires were provided to the subject. Items and questions were asked indirectly to assess how individuals perceive media information.

\section{Research design}

On a parent-teacher meeting at school, parents were invited to participate in the project and a sample was selected. Semi structured interview was conducted were parents were asked several questions about television programmes, internet usage, newspapers and magazines, book reading among children, video games and their use prevalence.

After the interviews, they were politely asked to fill questionnaires that had indirect questions related to various forms of media and how they perceive.

Similarly, students from each group were selected during a free period in the school and were interviewed about media and its necessity. It was noted that how their answers reflected their positive, negative, neutral attitude towards media. Later they were administered questionnaires and were given basic instructions. It was emphasized that none of their answers or identities would be revealed in the course of this research.

NOTE- Samples for questionnaires for ages 8-12, 13-17 years along with questionnaires for parents are attached in the end of the project. A copy of permission letter for conducting the research can also be referred from the last page.

\section{RESULTS}

The results have been divided into three sections-

1. Attitude of children towards media

2. Attitude of parents towards media

3. Comparison between the attitudes parents and children hold towards media. 


\section{ATTITUDE OF CHILDREN TOWARDS MEDIA}

Pie chart 1.1 represents the attitude of children from ages 8-17 years towards general media

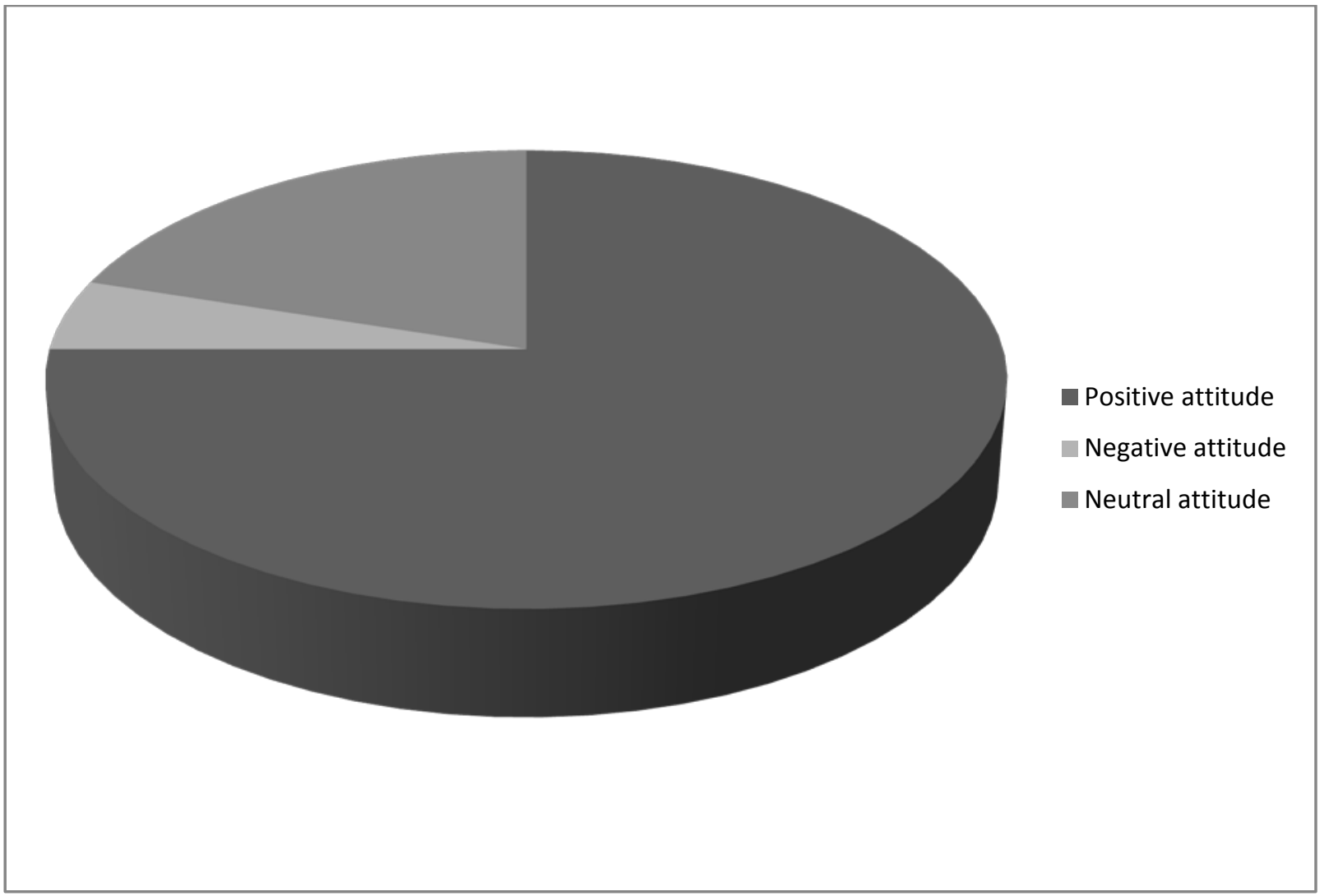

This pie chart indicates a general perception and attitude children hold towards media. Out of 60 children interviewed $75 \%$ of them mentioned about their positive affiliation with media and how different sections of media such as television, advertising, films, music, internet and magazines are an indispensable part of their lives. 
Table 1.2 indicates the rating girls and boys provide to different kinds of media on a scale of 1-5, with 5 being the highest (13-17 years)

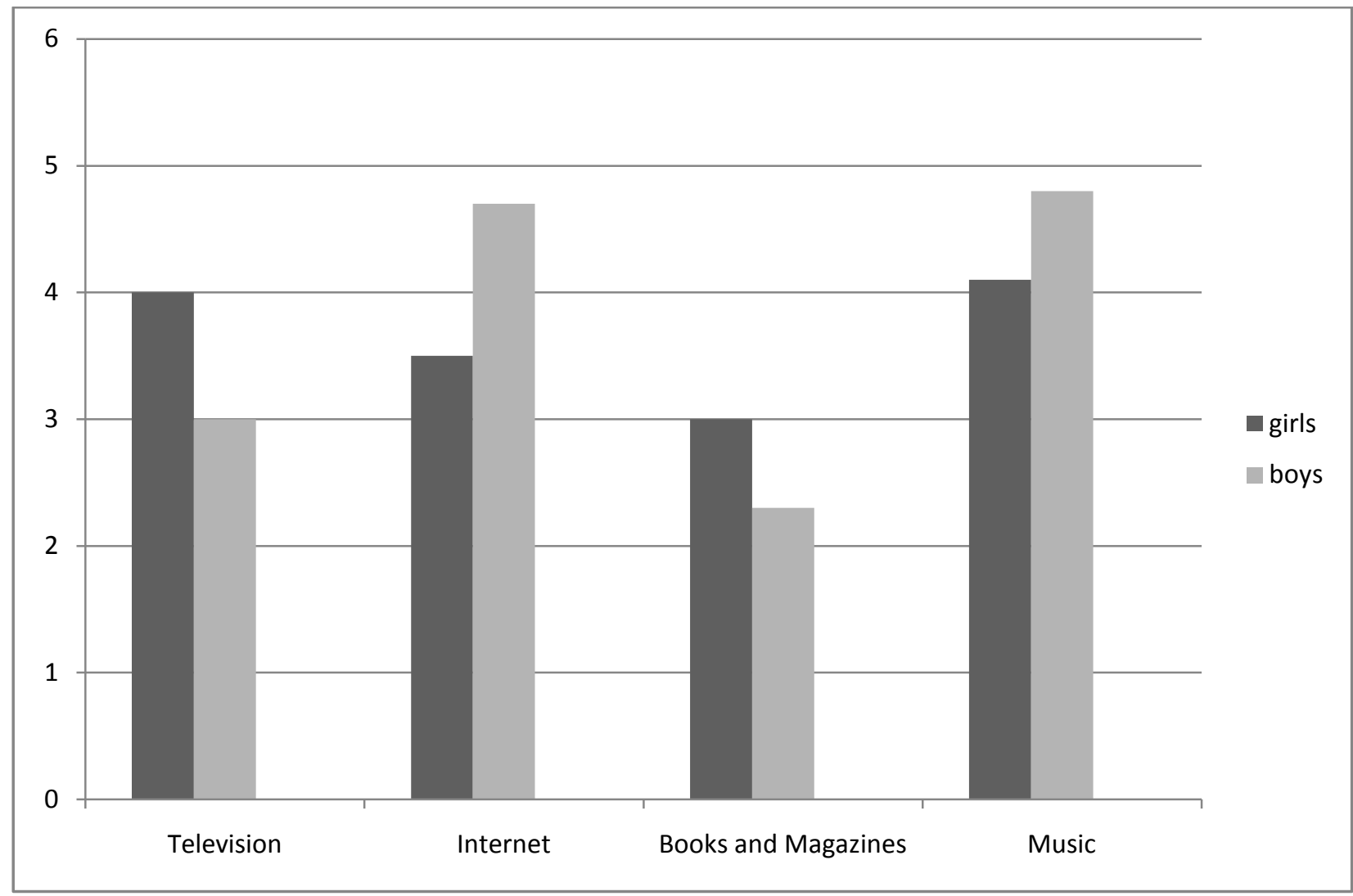

When the sample population consisting of 60 students were asked to rate different types of media on a scale of one to five, television on an average was rated 4 by girls, 3 by boys. Internet on the other hand held an average rating of 4.7 from boys and 3.5 from girls. Books and media were rated an average of 3 by girls and 2.3 by boys. Music was rated high by both genders with girls giving an average rating of 4.1 and boys giving an average rating of 4.8 . 


\section{ATTITUDE OF PARENTS TOWARDS MEDIA}

Pie chart 2.1 indicates attitude of parents towards media in general

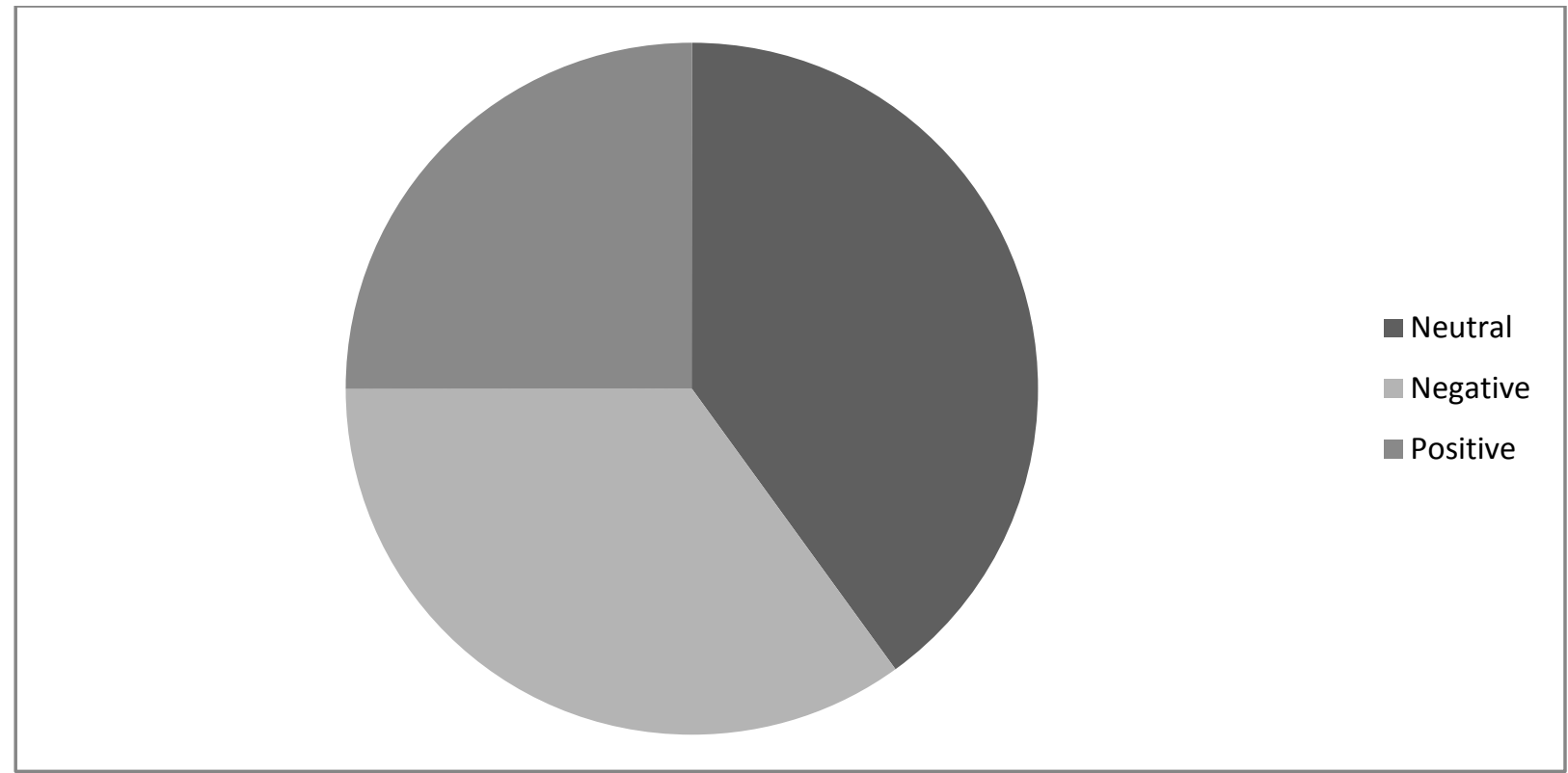

This table indicates that $40 \%$ of parents have a neutral attitude towards media, $35 \%$ have a negative and $25 \%$ have a positive attitude towards media

\section{COMPARISON OF ATTITUDES}

Table 3.1 indicates the rating of various types of media by parents and children on a scale of 1-5 with 5 being the highest.

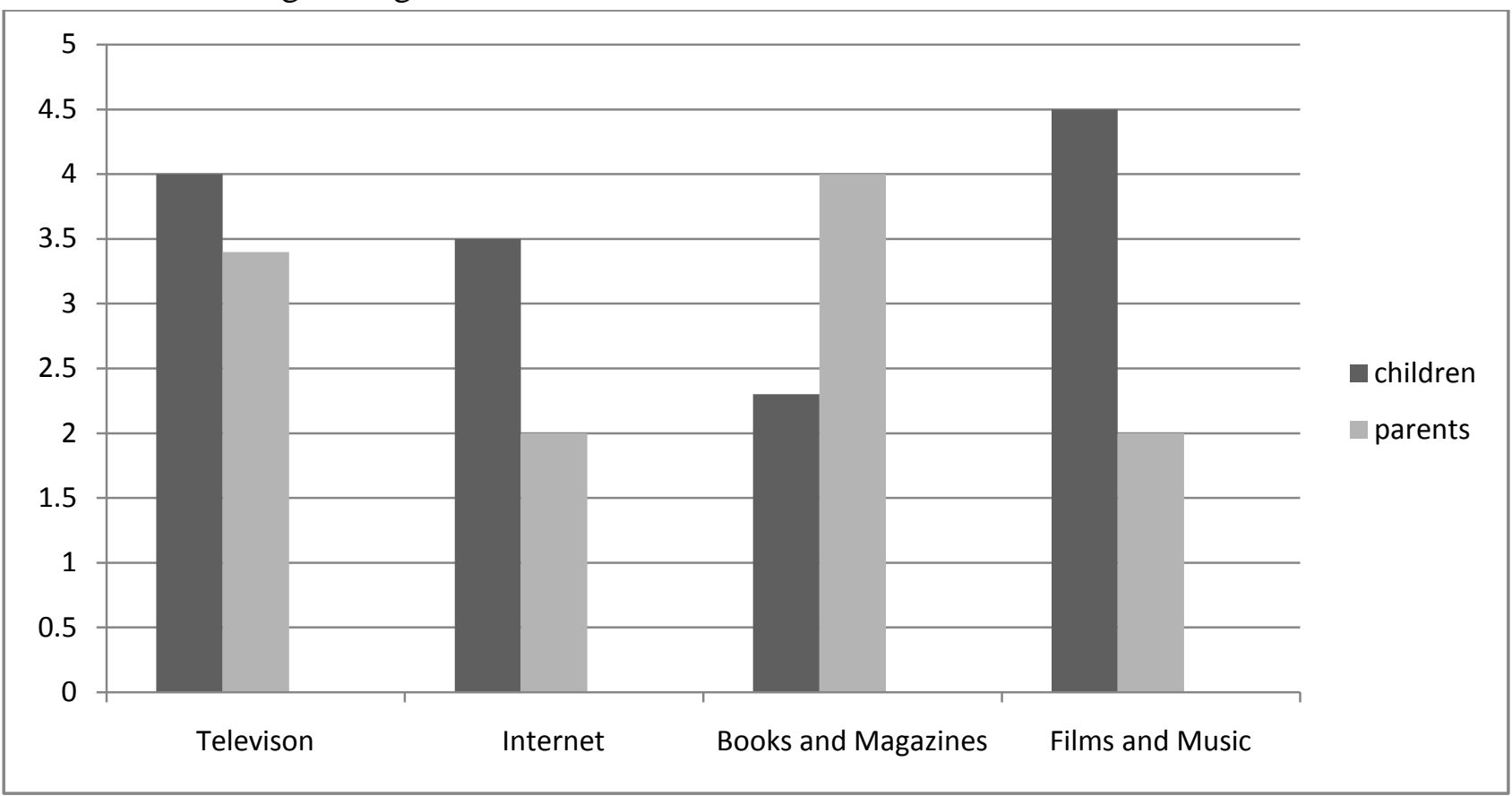




\section{How Parents and Their Children View Media? Comparing Attitudes of Parents and Children towards Media}

When parents and children were asked about media and their perception towards it, it was found that most of the children hold a positive attitude towards media while most of the parents hold a neutral attitude towards media.

\section{DISCUSSION OF RESULTS}

Out of 60 children interviewed $75 \%$ of them mentioned about their positive affiliation with media and how different sections of media such as television, advertising, films, music, internet and magazines are an indispensable part of their lives.

Unsurprisingly, only 5\% of children were found to hold a negative attitude towards media where they criticised certain aspects such as bad representation of females by media, boring television programmes, print media as lesser important etc.

$15 \%$ of the children believed to have a neutral view about the media; where according to them media doesn’t influence their actions, reactions and their daily lifestyles.

During the interview, these children were asked to explain how much good or bad they find media to be. Most of the students responded to this by saying that media helps in eliminating injustice from the society and keeps them well informed. Many girls replied to the question saying that media helps them know about various fashions and styles. Boys responded to same by mentioning how media, particularly internet, helps them socialise and know what goes around the world. These responses were provided by children from the age of 13 to 17 years.

When children from the age group of 8-12 years were asked about how much they like different types of media such as television, internet, video games etc, most of them replied by saying that they like media a lot. When asked to elucidate the same, they mention television helping them learn new things. Some of the children told about how video games help them learn better and how cartoons entertain them when they are bored doing the homework.

Different sets of questionnaires were provided to children from age group 8-12 years and children from ages 13-17 years as their interactions with media are different. The questionnaires included indirect questions pertaining to favourite television programme, video games, use of internet, advertisements etc.

When children from the ages 8-12 years were provided the questionnaires, an average population of them, particularly boys provided a high rating to video games (on an average 8 on a scale of 110 with ten being highest). Children also mentioned about their liking for reality shows and their

belief that it helps to procure talent. Many children opted for going for clothes, toys and food that are advertised more often on television and newspapers than the ones that are not.

This clearly indicates that children from ages 8-12 years hold positive attitude towards media and their perceptions about various events, situations and objects and shaped by media.

This is the possible reason as to why children from this age group are more prone to violence once they had seen it on television. It also explains the reason behind children emulating actors 


\section{How Parents and Their Children View Media? Comparing Attitudes of Parents and Children towards Media}

and forcing their parents to buy them products that are advertised by credible models or actors. A positive attitude ensures that they find video games attractive and cartoons lure them.

When students from ages 13-17 years were administered the questionnaires, most of the girls answered that they are either not satisfied with their body type because it is similar to the body type of females shown on television and in magazines or they wish to be like them. This indicates that television and magazines affect their body image which is because of their positive opinion about the information presented by the media.

Students from this age group generally believe that media defines roles and stereotypes for each gender and therefore show more preference towards media as it helps them learn the supposed norms and rules.

Most of the children from this age group have a somewhat negative attitude towards newspapers and news channels as they clearly state that they sell glamour and provide lesser resourceful information. They too believe in the power of advertising and prefer to buy branded clothes and products rather than going for average ones.

This indicates that children from ages 8-17 years on an average hold a positive attitude towards media and therefore are more often affected by it.

Most of parents when interviewed discussed about the ill effects of media and mentioned about how media influences change the way their children think, act and feel. They generally discussed the shortcomings of media and some of the parents ridiculed media persons who they felt do not feel responsible about what and how they are portraying themselves in front of a large audience. When interviewed, many parents presented a neutral attitude (40\%) wherein they discussed that media in different forms is only a source of knowledge and entertainment. They believed that media may influence their children behaviour, but they didn't blame it for a variety of negative behavioural changes. They mentioned that they allow their children to have decent contact with media, but they monitor their activities.

An average number of parents felt that media creates it difficult for them to deal with their children as it defines particular roles for each gender.

A few numbers of parents (30\%) have a negative attitude towards media and feel that media has bad effect on the way child acts and affects his/her language. Some of the parents blamed media for blind aping of western cultures while others feel that internet is responsible for their child's lesser concentration.

25\% population of parents in this research sample have a positive attitude towards media and feel that media helps their children in social interactions and helps him learn more. 


\section{How Parents and Their Children View Media? Comparing Attitudes of Parents and Children towards Media}

When parents were administered questionnaires, most of them wrote that they feel threatened by the ways media defines gender roles and how it forces their children to act or behave in certain ways. A large number of parents felt that there must be restrictions on what can be screened on television till 9:00pm to protect children from adultery or advertisements that prompt adolescents to buy harmful products. Although many parents presented no issues about their children using internet, yet they mentioned that they would prefer monitoring their child's activities.

Some of parents felt that media more or less doesn't have much role in westernization in this country and have a firm opinion that media; particularly print media helps their children to learn more.

Some of the parents presented concern about potential substance abuse that can be caused due to depiction of smoking, alcohol as fun on television and films, but many others believed that by controlling media exposure, they can determine the activities their child would indulge in.

Hence it was found that most of the parents have neutral attitude towards media where they find it a boon whose exposure shall be controlled.

When parents and children were asked about media and their perception towards it, it was found that most of the children hold a positive attitude towards media while most of the parents hold a neutral attitude towards media.

When asked to rate different types of media on a scale of 1-5 with five being the highest, television was rated at an average of 2.5 by the parents which represent neutral and 4 by the children. Internet was given an average rating of 3.5 by the children, indicating positive attitude and 2 by the parents, indicating a negative attitude. Books was given an above average rating of 4 by the parents and a below average rating of 2.3 by the children. Films and music was given a high rating of 4.5 by children and a low rating of 2 by the parents, indicating a negative attitude of parents towards films and music.

Hence when compared, it shall be noted that parents have a neutral attitude towards media, while children have a positive attitude towards media.

\section{SUMMARY AND CONCLUSION}

This project was conducted to ascertain how parents and children view media. It was hypothesized that children on a general level would have a positive attitude towards media while parents would either have a neutral or a negative attitude towards media. In this project, media referred to various means of social communication such as television, films, books, magazines, video games, internet, newspapers etc. Attitude on the other hand referred to an opinion that one has about someone or something. It can reflect a favorable, unfavorable, or neutral judgment. 


\section{How Parents and Their Children View Media? Comparing Attitudes of Parents and Children towards Media}

The main objective was to find out parental and children's attitude towards media. The aim herein was to understand how children are prone to being affected by the content presented by media. The project was also conducted with a view to understand how various dynamics of media affects old and young in different ways.

A sample of 60 parents and 60 children from the age group 8-17 years were selected as the sample populations. Parents below the age of 45 years were selected.

The sample was administered questionnaires which presented indirect questions about what and how they perceive media to be. The sample was also interviewed to understand their beliefs and opinions about various kinds of media.

Data was collected in qualitative and quantitative measures. Qualitative measure involved knowing the depth of attitude of sample size holds for media and understanding how possibly media affects them. Quantitative measures involved the sample providing rating to several types of media along with reasons.

The data collected was then analysed and it was concluded that children on an average have positive attitude towards media. They feel that media defines the way people think, feel, act and behave. Most of them revealed to be directly influenced by media that influences the products they buy, clothes they wear, language they use, socialization etc.

Most of the parents on the other hand provided a neutral attitude towards media, where they presented a notion that media is a reservoir of knowledge, but their child's usage of this reservoir shall be limited. Most of the parents discussed about how they monitor their child's activities so that s/he takes up only the required and relevant information.

Some of the parents had a negative attitude towards media where they expressed concern related to the content shown on television and movies. Although they felt that their children should focus more on print media, yet children displayed a rather neutral attitude towards reading newspapers and books.

Hence it may be concluded that children on an average have a more positive attitude towards media, while parents hold a neutral or negative attitude towards it.

It shall also be noted that through this project, the hypothesis is proved. Further research on this topic can be diverted at understanding how these attitudes define the manner in which children are affected by media and what shall be done to avoid children being exposed to explicit content. Researches on how parents can monitor their child's activities and reduce media influence can also be 


\section{REFERENCES}

Alexander, Alison. 1994. The Effect of Media on Family Interaction. In Media, Children, and the Family: Social Scientific, Psychodynamic, and Clinical Perspectives, edited by DolfZillman, Jennings Bryant and Aletha C. Huston (51-59). Hillsdale, NJ: Lawrence Erlbaum

American Academy of Pediatrics. 2007a. Television and the Family. www.aap.org/family/tv1.htm. (Accessed on July 10, 2014).

Cantor, J. (1996). Television and children's fear. In T. MacBeth (Ed.), Tuning in to young viewers: Social science perspectives on television (pp. 87-115). Thousand Oaks, CA: Sage Publications.

Forcier, Richard C. (1996). “The Computer as a Productivity Tool in Education”.Prentice Hall Company in United States of America.Hoffner, C., \& Cantor, J. (1985). Developmental differences in responses to a television character's appearance and behavior. Developmental Psychology, 21, 10651074.

Gentile, D.A., and J.R. Gentile (2008). "Violent Video Games as Exemplary Teacher: A Conceptual Analysis.” Journal of Youth and Adolescence 37(2):127-141.

Karson, E., McCloy, S. and Bonner, G. (2006). “An examination of Consumers’ Attitudes and Beliefs towards Web Site Advertising”. Journal ofCurrent Issues \& Research in Advertising, Vol. 28, pp. 77-91.

Pine, Karen J., Penny Wilson and Avril S. Nash. 2007. The Relationship Between Television Advertising, Children's Viewing and Their Requests to Father Christmas. Journal of Developmental \&BehavioralPediatrics, 28 (6): 456-461

Wilman, A.R. 1983. Parental Influence and Children's Responses to Television Advertising. Journal of Advertising, 12: 12-18

Wolin, L., Korgaonkar, P. and Lund, D. (2002). "Beliefs, Attitudes and Behavior towards Web Advertising”, International Journal of Advertising, Vol. 21 (1), pp. 87-113.

Young, Brian M., de Anne Bruin and Lynne Eagle. 2003. Attitudes of Parents Toward Advertising to Children in the UK, Sweden and New Zealand. Journal of Marketing Management, 19: 475-49 